\title{
Effects of 3D Printing-Line Directions for Stretchable Sensor Performances
}

\author{
Chi Cuong Vu (D), Thanh Tai Nguyen, Sangun Kim $\mathbb{D}$ and Jooyong Kim *(D) \\ Department of Organic Materials and Fibers Engineering, Soongsil University, Seoul 156-743, Korea; \\ cuongvc287@gmail.com (C.C.V.); ntt16895@gmail.com (T.T.N.); tkddns10723@naver.com (S.K.) \\ * Correspondence: jykim@ssu.ac.kr; Tel.: +82-010-8720-0631
}

Citation: Vu, C.C.; Nguyen, T.T.;

Kim, S.; Kim, J. Effects of 3D

Printing-Line Directions for Stretchable Sensor Performances. Materials 2021, 14, 1791. https:// doi.org/10.3390/ma14071791

Academic Editor: Maria Magdalena Pastor

Received: 27 February 2021

Accepted: 1 April 2021

Published: 5 April 2021

Publisher's Note: MDPI stays neutral with regard to jurisdictional claims in published maps and institutional affiliations.

Copyright: (c) 2021 by the authors. Licensee MDPI, Basel, Switzerland. This article is an open access article distributed under the terms and conditions of the Creative Commons Attribution (CC BY) license (https:// creativecommons.org/licenses/by/ $4.0 /)$.
Abstract: Health monitoring sensors that are attached to clothing are a new trend of the times, especially stretchable sensors for human motion measurements or biological markers. However, price, durability, and performance always are major problems to be addressed and three-dimensional (3D) printing combined with conductive flexible materials (thermoplastic polyurethane) can be an optimal solution. Herein, we evaluate the effects of $3 \mathrm{D}$ printing-line directions $\left(45^{\circ}, 90^{\circ}, 180^{\circ}\right)$ on the sensor performances. Using fused filament fabrication (FDM) technology, the sensors are created with different print styles for specific purposes. We also discuss some main issues of the stretch sensors from Carbon Nanotube/Thermoplastic Polyurethane (CNT/TPU) and FDM. Our sensor achieves outstanding stability (10,000 cycles) and reliability, which are verified through repeated measurements. Its capability is demonstrated in a real application when detecting finger motion by a sensor-integrated into gloves. This paper is expected to bring contribution to the development of flexible conductive materials-based on $3 \mathrm{D}$ printing.

Keywords: 3D printing; stretchable sensors; printing-line direction; thermoplastic polyurethane

\section{Introduction}

Three-dimensional (3D) printing enables us to create complex shapes using fewer materials than traditional manufacturing methods [1-3]. In which, fused deposition modeling (FDM) is a 3D printing process that uses a continuous filament from thermoplastic materials [4-6]. The filament is heated and extruded by a nozzle. Each printed layer is laid down one at a time until the object is complete. This method has become popular, because it provides a cleaning process, easy-to-use, and cost-effective. Nowadays, stretchable sensors, which are fabricated by 3D printing, have demonstrated important roles during the evolution of electronic skin [7,8], wearable electronics [9-11], and biomedicine [12,13].

When considering flexible parts created by 3D printing, thermoplastic polyurethane (TPU) is well known. TPU possesses high elasticity (as rubber), tear or abrasion resistance, high elongation, as well as thermal stability [14-16]. When containing conductive components (carbon nanotube, CNT), CNT/TPU is definitely a highlight material to fabricate the stretch sensors [17-20]. Following this approach, there are many great studies in the stretch sensing field, which are enhanced with advanced materials based on FDM printing [21-25]. For example, Josef et al. [26] developed 3D printed highly elastic strain sensors of multiwalled carbon nanotube/thermoplastic polyurethane (MWCNT/TPU) nanocomposites. Gauge factors achieve 176. Dong et al. [10] presented CNT/TPU nanocomposites via non-covalent interactions to enhance the performance of the stretch sensors. These 3D sensors demonstrated excellent properties with a high gauge factor and large detectable strain $(250 \%)$. In addition, Saeb et al. [27] developed high anisotropic, flexible, constrictionresistive sensors. The sensing elements and conductive interconnects are 3D-printed from a carbon-nanotube-reinforced polylactic acid (PLA-CNT). The sensor parameters can be adjusted by controlling the air gap between printed adjacent tracks, infill density, and 
build orientation. However, the characteristics of the printing-line directions have not been discussed in depth.

Here, we focus on the one-step processing of stretchable sensors using the TPU material and FDM method. Especially, the effects of printing-line directions $\left(45^{\circ}, 90^{\circ}, 180^{\circ}\right)$ on sensor performances are evaluated in detail. The sensor types are printed by a rebuilt RepRap Prusa I3 3D printer, which is an ideal option for a low-cost FDM 3D printer. The printing parameters are set up and the thickness of the sensors is about $0.4 \mathrm{~mm}$. We observe that the printing direction at $45^{\circ}$ is the best solution to enhance the characteristics of the sensor. Besides, the sensor is integrated into gloves to detect finger motions. This prototype application explains the potential of our sensor in smart garments.

Some previous studies on the effects of geometry (shapes and structures) on the strain sensors [28] and 3D printing samples [29-31] are the motivation for the paper. We realize that the geometric approach is easy, fast, and low-cost to improve sensor performance in wearable systems. Accordingly, this research is expected to be a standardization for 3D-printing strain sensors.

\section{Materials and Methods}

\subsection{Materials}

Conductive flexible filament (TPU/CNT) was acquired from Black Magic 3D. The diameter of CNTs (PI-ETPU, Palmiga Innovation, Jonstorp, Sweden) is about $9.5 \mathrm{~nm}$ and the length of CNTs in the TPU filaments is about $3 \mu \mathrm{m}$, according to information from the product supplier. The characteristics of TPU can ensure flexibility and good compatibility with 3D printing. The conductivity of the filament is under $1.25 \Omega-\mathrm{cm}$. The diameter is $1.75 \mathrm{~mm}$ and tolerance is $+/-0.03 \mathrm{~mm}$. 3D FDM printer (RepRap Prusa I3) parts were prepared from Naserpop Com., Incheon, South Korea.

\subsection{Printing Method}

Three types of samples are designed in a rectangle shape on Solidworks software (version 2019, Solidworks Corp., Waltham, MA, USA) and then processed via Repetier-Host software (version 2.1.6, Hot-World GmbH \& Co. KG, Willich, Germany) with a dimension of $4 \mathrm{~mm} \times 60 \mathrm{~mm}$, and a thickness of $0.4 \mathrm{~mm}$. Before printing, the conductive flexible TPU filament is dried at $70^{\circ} \mathrm{C}$ for four hours in order to remove moisture. This procedure helps the printed samples have better resistance. These sensors are constructed in three different types at the printing-line directions $\left(45^{\circ}, 90^{\circ}, 180^{\circ}\right)$ with a nozzle size of $0.2 \mathrm{~mm}$. Each sample will be printed in two layers. The thickness of one layer is $0.2 \mathrm{~mm}$. This makes the printing is easy; the sensors are thin and stretchable.

TPU is flexible. Hence, the filament is easy to get stuck or flat between the rollers (as shown in Figure 1a), owing to heat conduction [30-32]. Herein, the heat transfer from one end to another of the distance (L) of TPU filament can be considered as heat conduction. Equation (1) describes this process.

$$
\frac{\mathrm{Q}}{\mathrm{t}}=\frac{\mathrm{k} * \mathrm{~A} \cdot\left(\mathrm{T}_{\text {hot }}-\mathrm{T}_{\text {cold }}\right)}{\mathrm{L}}
$$

where $\mathrm{Q}$ is the heat transfer in time, $\mathrm{k}$ is the thermal conductivity of TPU, A is the area of cross-section filament, $\mathrm{T}$ is the temperature, and $\mathrm{L}$ is the distance from the hot end to the cold end of the filament.

Some of the solutions can be used to avoid the filament sticking issue, for example, increasing the area of the cross-section of extending the distance $(\mathrm{L})$ by high flow rate (the rate of plastic exiting the extruder's nozzle) or decreasing the printing temperature. Herein, we set up the temperature at $230{ }^{\circ} \mathrm{C}$ in order to minimize the possibility of blockages and the appearance of air bubbles in the samples. In addition, the speed of the extruder head is another important parameter to stop or start deposition. This value (at the speed of $20 \mathrm{~mm} / \mathrm{s}$ ) will create stable printing lines without interruption. 
The FDM method presents a disadvantage when using available conductive filaments (CNT/TPU). Heat treatment/print will generate many spaces between the conductive particles, and the concentration of the CNT per sample reduces. This leads to a significant increase in the resistance of the sensors. These issues can be resolved by decreasing the temperature or changing the material (increasing the rate of CNTs). However, this method also increases the manufacturing-cost and it needs more experimentations.

a

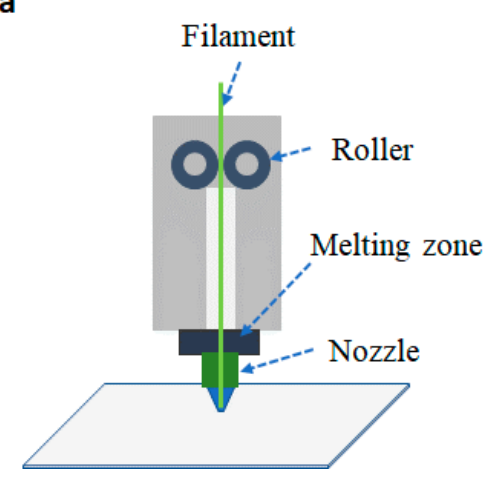

b

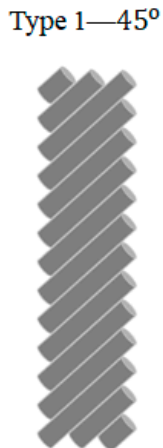

Type $2-90^{\circ}$

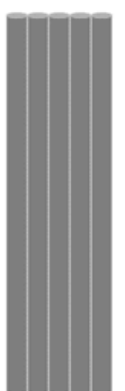

Type $3-180^{\circ}$

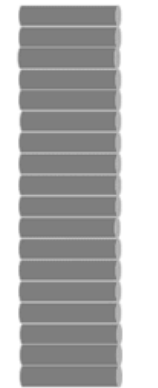

Figure 1. (a) Fused deposition modeling (FDM), (b) three structures $\left(45^{\circ}, 90^{\circ}, 180^{\circ}\right)$ of threedimensional (3D) printing-line directions.

\section{Results and Discussion}

\subsection{Structure of the Sensors}

Figure 1a shows the process of the fused deposition modeling (FDM) in 3D printing technology. Conductive filament (CNT/TPU) is fed from a large spool through a moving, heated printer extruder head, and it is deposited on the growing work. The position and speed of the extruder head will move under the control of a computer to define the sensor shapes. Melting temperature and extrusion speed are two main parameters, which define the quality of the printing surface. There are three types due to the direction of the printing-lines at $45^{\circ}, 90^{\circ}$, and $180^{\circ}$, as described in Figure $1 \mathrm{~b}$.

Using scanning electron microscopy (Gemini SEM 300, ZEISS Corp., Jena, Germany), the magnified images are shown in Figure 2, at $0.3 \mathrm{~mm}, 100 \mu \mathrm{m}$, and $1 \mu \mathrm{m}$, respectively. We observe that CNTs are about $9.5 \mathrm{~nm}$ in diameter and homogeneously dispersed in TPU filament. The majority of these carbon nanotubes are fractured under strain/release cycles, inducing the resistance change of the sensors.

\subsection{Characteristics of the Sensors}

In order to analyze the fabricated sensor's electrical characteristics, we develop an experiment with a customized universal testing machine. As shown in Figure 3a, this system includes a force load cell from Dacell Co. Ltd., Seoul, Korea, a source meter (Keysight B2902A), and a computer. The sensitivity of sensors is demonstrated through the gauge factor (Equation (2)).

$$
\mathrm{GF}=\frac{\Delta \mathrm{R} / \mathrm{R}}{\varepsilon}=\frac{\Delta \mathrm{R} / \mathrm{R}}{\Delta \mathrm{L} / \mathrm{L}}
$$

where GF is the gauge factor, $R$ is the initial resistance, $\Delta R$ is the absolute change in resistance, $\mathrm{L}$ is the initial length, and $\Delta \mathrm{L}$ is the absolute change in length. 

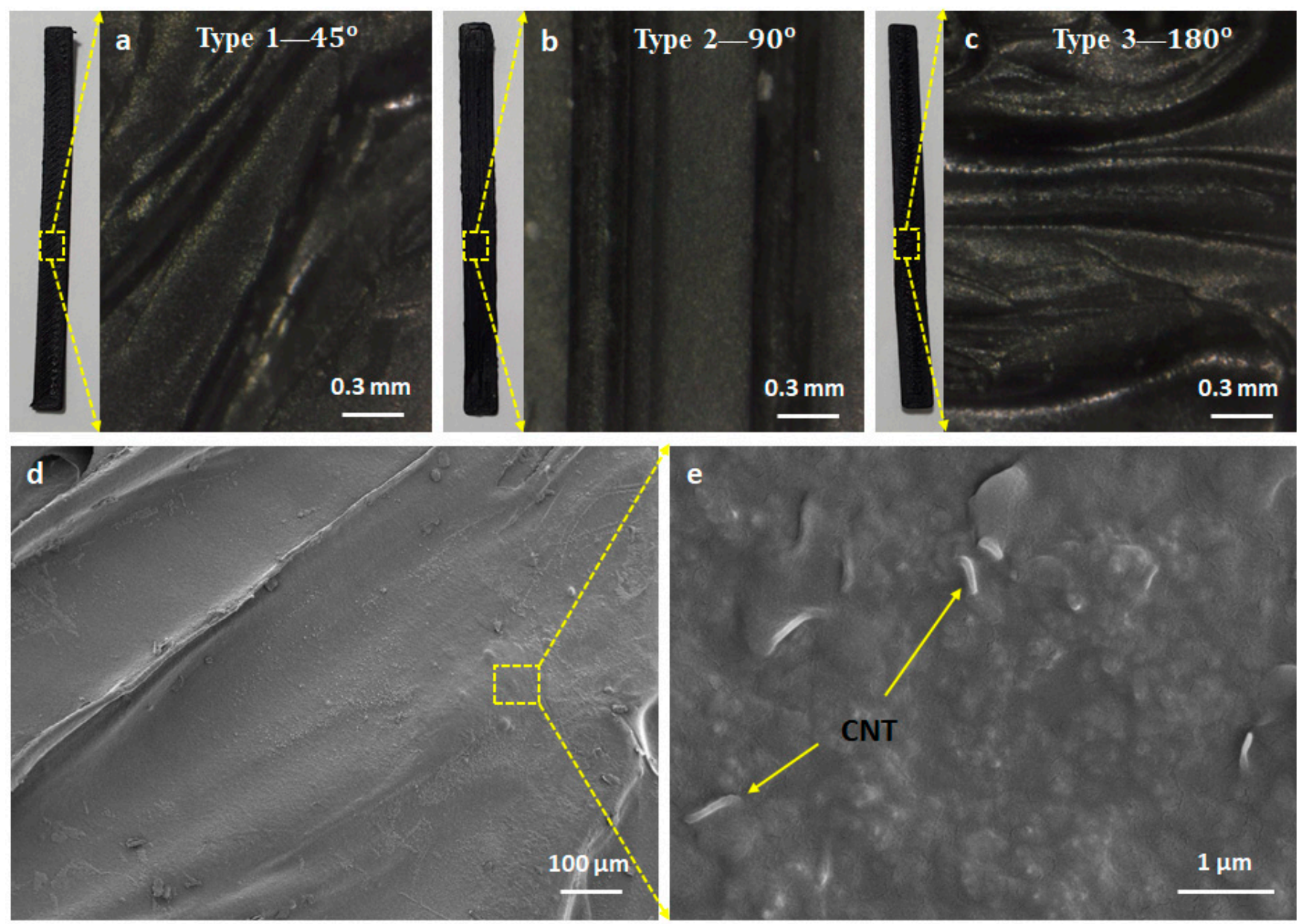

Figure 2. Scanning electron microscope (SEM) images of the sensors, consisting of (a) Type $1-45^{\circ}$ at $0.3 \mathrm{~mm}$, (b) Type 2-9 $90^{\circ}$ at $0.3 \mathrm{~mm}$, (c) Type $3-180^{\circ}$ at $0.3 \mathrm{~mm}$, (d) SEM of the printing line at $100 \mu \mathrm{m}$, and (e) SEM of the printing line at $1 \mu \mathrm{m}$.
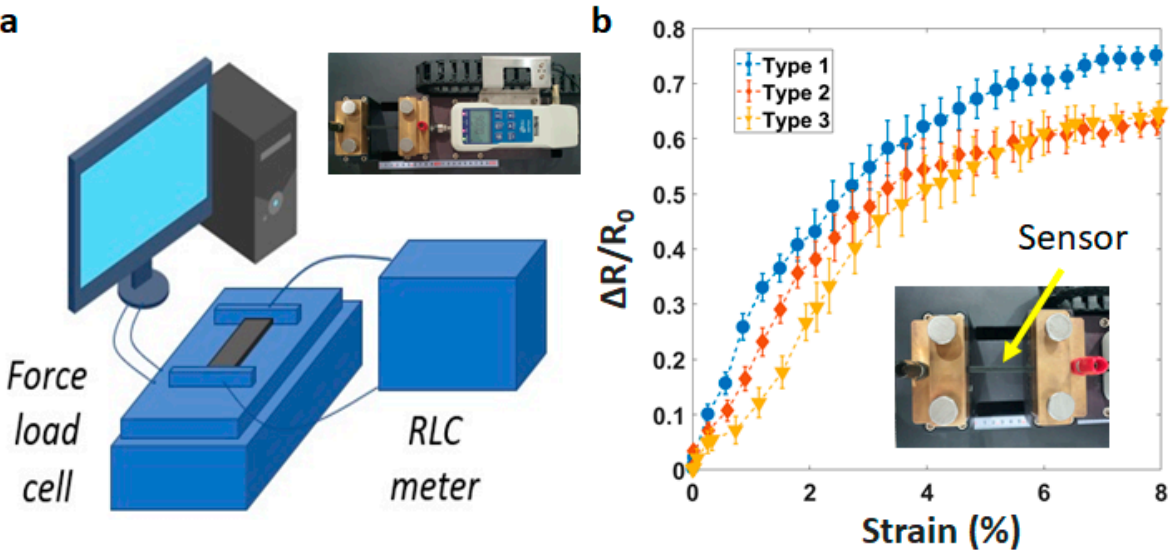

Figure 3. (a) Universal testing machine (UTM), (b) Sensitivity of the sensors with type $1-45^{\circ}$, type $2-90^{\circ}$, type $3-180^{\circ}$.

Five samples of each type are tested and averaged at the strain speed of $1 \mathrm{~mm} / \mathrm{s}$. The largest sensitivity is the printing line at $45^{\circ}$ (Figure 3b). GF is about 21.5 when stretching from $0-2 \%$, and 16.2 when stretching from $2-4 \%$. However, it drops to 10 when stretching from $4-8 \%$. For other printing lines $\left(90^{\circ}\right.$ and $\left.180^{\circ}\right), \mathrm{GF}$ is about 12.5 when stretching from $0-4 \%$, and 5.5 when stretching from $4-8 \%$. The acceptable performance of a strain sensor 
is determined by the ability to detect changes in structure under minimum deformation. This parameter is shown significantly in the sensitivity (GF). Actually, all three types of our sensors $\left(45^{\circ}, 90^{\circ}, 180^{\circ}\right)$ demonstrate good performances when compared to the samples of Christ et al. with GF 3.0 [33], Rahman et al. with GF 3.15 [34], or Yao et al. with GF 6.6 [35].

Hysteresis represents the historical dependence of a system. It is often evaluated by the difference in the sensor signals at two phases (strain and release) of a cycle. We investigate the hysteresis of sensors in Figure 4a. There is a significant difference between the printing-line direction at $45^{\circ}$ and the two others. The maximum hysteresis is under $10 \%$ for line at $45^{\circ}$. Meanwhile, the value is over $30 \%$ for lines at $90^{\circ}$ and $180^{\circ}$.

The response time refers to the time span between the sensor signal and the mechanical stimulation of the universal testing machine (UTM). The response time can be estimated as $120 \mathrm{~ms}$ in the increasing step of the tension, as described in Figure $4 \mathrm{~b}$. Besides, the recovery time is defined as the time for the sensor to return to the baseline value after removing tension. Figure $4 \mathrm{c}$ shows a short recovery time of less than $100 \mathrm{~ms}$. The delay time is caused by the viscoelastic nature of TPU and the re-connectivity between CNT-particles under strain force. A fast response/recovery time will ensure the rapid electrical property in a practical application. Based on those results, the printing-line direction at $45^{\circ}$ shows a good solution in real applications when creating the stretch sensors from FDM technology.
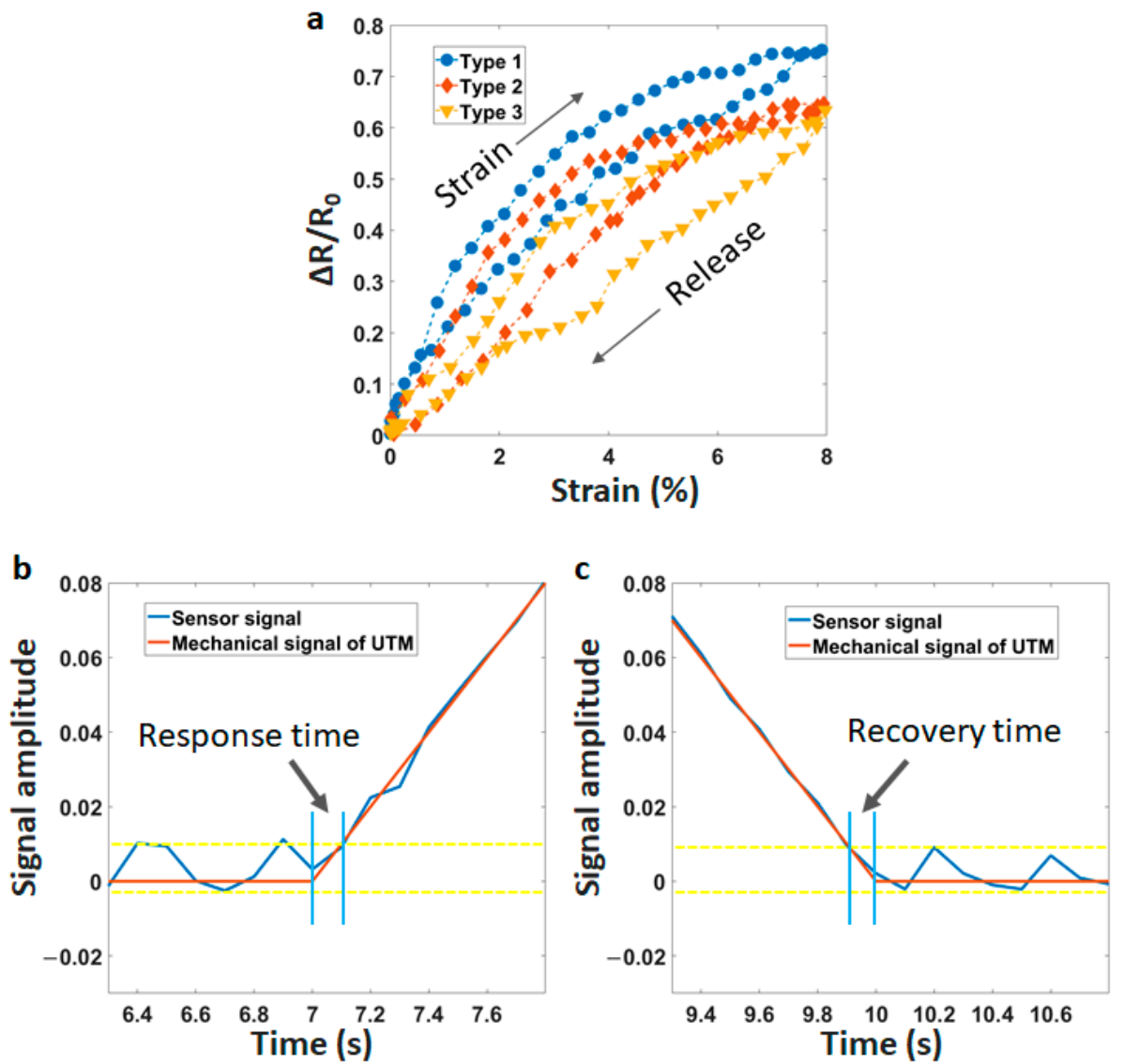

Figure 4. (a) Hysteresis of the sensors with type $1-45^{\circ}$, type $2-90^{\circ}$, type $3-180^{\circ}$, (b) Response time, and (c) Recovery time.

We also investigate the dynamic performance of the sensor (Figure 5a). It is clear that the sensor has a stable response under a wide mechanical frequency range from $0.75 \mathrm{~Hz}$ to $6 \mathrm{~Hz}$. Most of the wearable devices work around room temperature $\left(\sim 25^{\circ} \mathrm{C}\right)$. Therefore, the operation of the sensor is tested in the temperature range of 20 to $30^{\circ} \mathrm{C}$. This will ensure that the sensor potential is in a realistic application. After testing, Figure $5 \mathrm{~b}$ describes 
the effect of temperature on the performance. We observed that the resistance has a little change $(<7 \%)$ in the temperature range of 20 to $30{ }^{\circ} \mathrm{C}$. This result is achieved due to the filament being processed through the melting step. Accordingly, the sensor is less affected by the temperature.
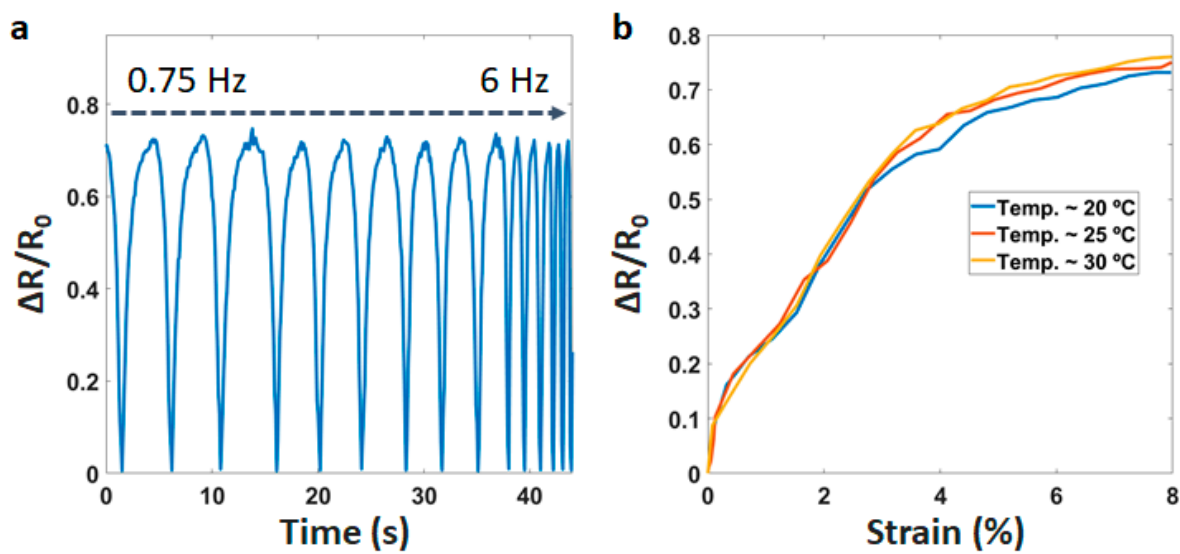

Figure 5. (a) Sensitivity of the sensor at different frequencies, (b) Resistance changes at different temperatures.

Figure 6 describes the stable electrical functionality and mechanical integrity during multiple strain/release cycles (based on the strain force of UTM machine). We can observe that the durability of the sensor is over 10,000 cycles at the frequency of $2 \mathrm{~Hz}$. There is a small difference at the limit of sensing $\sim \%$. The reason for this behavior is the deformation (permanent) in the structure under pressure, leading to a small change in the sensing limitation.

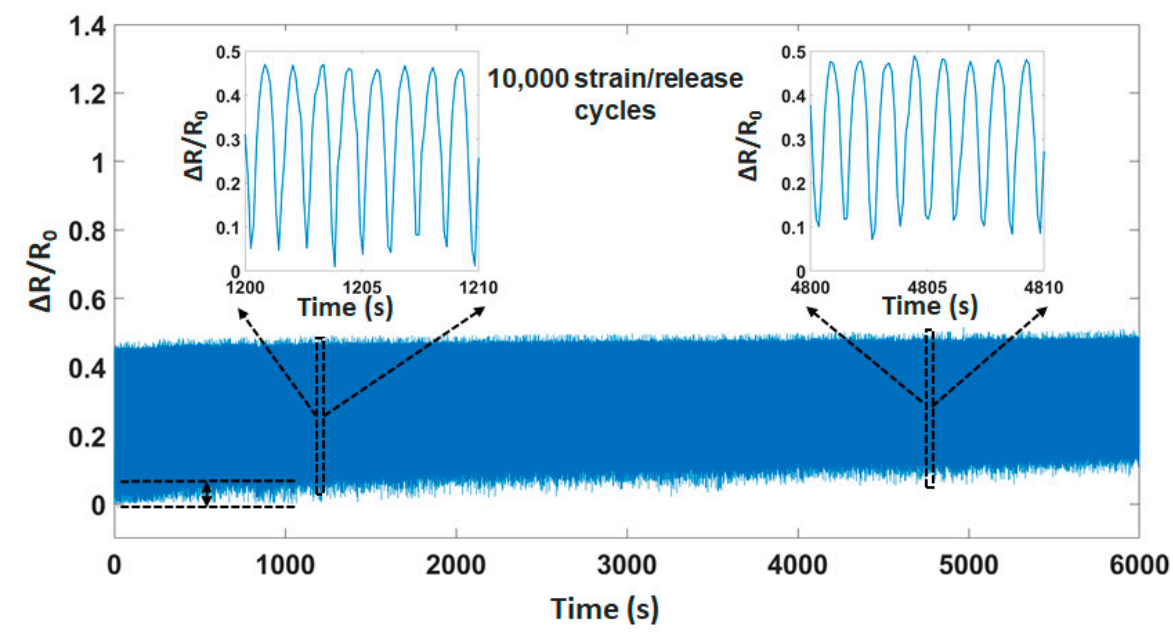

Figure 6. Durability of the sensor in 10,000 strain/release cycles.

\subsection{Applications}

The sensor is attached to a glove for tracking finger motions to demonstrate the potential applications (Figure 7a). The electrical wires (AWG 32) are fixed on both edges of the sensor using instant adhesives and stretchable silver pastes, as shown in Figure $7 \mathrm{~b}$ (from Dycotec Materials Ltd., Calne, UK). The signal processing system is an integrated circuit (Figure 7c), consisting of an nRF52 module (analog/digital converter-ADC, microcontroller unit-MCU, Bluetooth) and a lipo-battery (3.7 V). Using a voltage divider circuit, the analog signals are sampled/digitized and converted into digital signals. The resolution is set up between 0 to $3 \mathrm{~V}$ into digital values from 0 to $1023(3 / 1023 \sim 0.003 \mathrm{~V}$ or $3 \mathrm{mV}$ per unit). The input signal is read every $10 \mathrm{~ms}$. 
The finger movement is tested when increasing the bending angle from 0 to $45^{\circ}$ (Figure 7d). The sensor signal immediately increases following the bending angle, but makes a slight noise at the start and the end phases. This can be explained by the elastic features of the glove material, which makes it difficult to keep the finger position. We suggest using a digital filter that is easy to solve these noises. This testing has demonstrated the ability of our sensor in wearable applications.
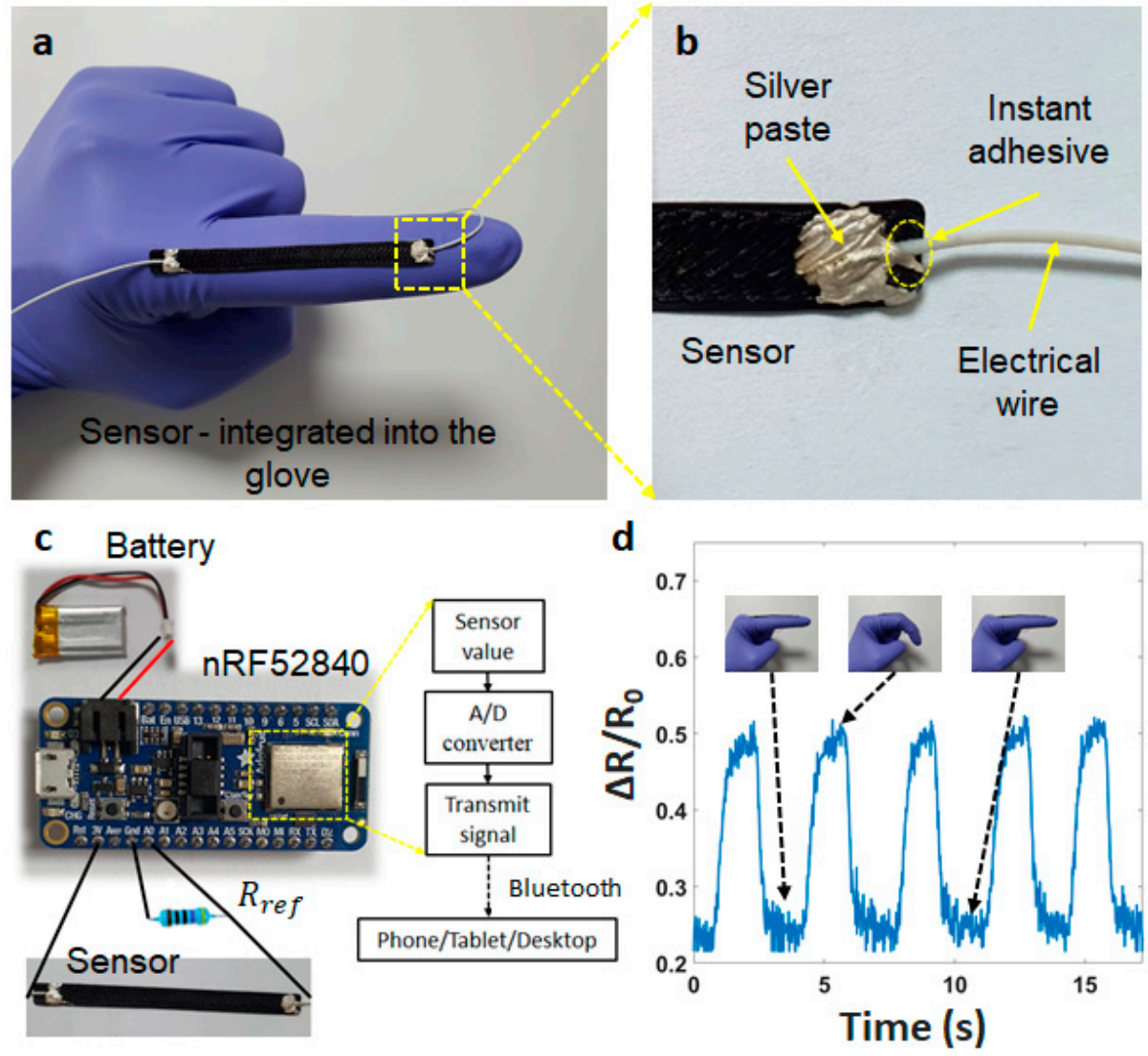

Figure 7. (a) Structure of the sensor integrated into the glove, (b) Structure of the connection, (c) Integrated device, and (d) Resistance changes of the finger when bending at $45^{\circ}$ and recovering.

\section{Conclusions}

In this work, we have evaluated the effects of the printing-line directions $\left(45^{\circ}, 90^{\circ}\right.$, $180^{\circ}$ ) on the performance of the strain sensor. The printing line at $45^{\circ}$ improved the characteristics, especially GF, from 12.5 to 21.5 , and hysteresis under $10 \%$ when compared to two other printing lines. In addition, our sensor exhibited a fast response time of $120 \mathrm{~ms}$ and an excellent stability of 10,000 cycles. This sensor also demonstrated its ability to detect finger bending movements in a real application. Although $3 \mathrm{D}$ printing is not compatible with mass production due to it being a slow process and difficult to speed up. The sensor, fabricated by FDM and CNT/TPU filament, still provides promising advantages for developing personalized garments in human motion monitoring, human-machine interface, or intelligent robots.

Author Contributions: Conceptualization, C.C.V., T.T.N. and J.K.; validation C.C.V., T.T.N., S.K. and J.K.; formal analysis, C.C.V., T.T.N., S.K. and J.K.; investigation, C.C.V. and T.T.N.; writing-original draft preparation, C.C.V. and T.T.N.; writing-review and editing, C.C.V., S.K. and J.K.; supervision, C.C.V. and J.K; Project Administration, C.C.V., S.K. and J.K; Funding Acquisition, C.C.V. and J.K. All authors have read and agreed to the published version of the manuscript.

Funding: This research was partly supported by the National Research Foundation of Korea (NRF2019R1A2C2005933) grant funded by the Korea Government (MSIT) and Korea Institute for Ad- 
vancement of Technology (KIAT) grant funded by the Korea Government (MOTIE) (P0002397, HRD program for Industrial Convergence of Wearable Smart Devices).

Institutional Review Board Statement: Not applicable.

Informed Consent Statement: Not applicable.

Data Availability Statement: The data used to support the findings of this study are available from the corresponding author.

Acknowledgments: This research was partly supported by the National Research Foundation of Korea (NRF-2019R1A2C2005933) grant funded by the Korea Government (MSIT) and Korea Institute for Advancement of Technology (KIAT) grant funded by the Korea Government (MOTIE) (P0002397, HRD program for Industrial Convergence of Wearable Smart Devices).

Conflicts of Interest: The authors declare no conflict of interest.

\section{References}

1. Ngo, T.D.; Kashani, A.; Imbalzano, G.; Nguyen, K.T.Q.; Hui, D. Additive Manufacturing (3D Printing): A Review of Materials, Methods, Applications and Challenges. Compos. Part B Eng. 2018, 143, 172-196. [CrossRef]

2. Egorov, V.; Gulzar, U.; Zhang, Y.; Breen, S.; O’Dwyer, C. Evolution of 3D Printing Methods and Materials for Electrochemical Energy Storage. Adv. Mater. 2020, 32, 2000556. [CrossRef]

3. Prendergast, M.E.; Burdick, J.A. Recent Advances in Enabling Technologies in 3D Printing for Precision Medicine. Adv. Mater. 2020, 32, 1902516. [CrossRef] [PubMed]

4. Akhoundi, B.; Behravesh, A.H.; Bagheri Saed, A. Improving Mechanical Properties of Continuous Fiber-Reinforced Thermoplastic Composites Produced by FDM 3D Printer. J. Reinf. Plast. Compos. 2019, 38, 99-116. [CrossRef]

5. Ajay Kumar, M.; Khan, M.S.; Mishra, S.B. Effect of Machine Parameters on Strength and Hardness of FDM Printed Carbon Fiber Reinforced PETG Thermoplastics. Mater. Today Proc. 2020, 27, 975-983. [CrossRef]

6. Garzon-Hernandez, S.; Arias, A.; Garcia-Gonzalez, D. A Continuum Constitutive Model for FDM 3D Printed Thermoplastics. Compos. Part B Eng. 2020, 201, 108373. [CrossRef]

7. Chen, Y.; Deng, Z.; Ouyang, R.; Zheng, R.; Jiang, Z.; Bai, H.; Xue, H. 3D Printed Stretchable Smart Fibers and Textiles for Self-Powered e-Skin. Nano Energy 2021, 84, 105866. [CrossRef]

8. Herbert, R.; Lim, H.-R.; Yeo, W.-H. Printed, Soft, Nanostructured Strain Sensors for Monitoring of Structural Health and Human Physiology. ACS Appl. Mater. Interfaces 2020, 12, 25020-25030. [CrossRef] [PubMed]

9. Gao, Y.; Yu, G.; Shu, T.; Chen, Y.; Yang, W.; Liu, Y.; Long, J.; Xiong, W.; Xuan, F. 3D-Printed Coaxial Fibers for Integrated Wearable Sensor Skin. Adv. Mater. Technol. 2019, 4, 1900504. [CrossRef]

10. Xiang, D.; Zhang, X.; Li, Y.; Harkin-Jones, E.; Zheng, Y.; Wang, L.; Zhao, C.; Wang, P. Enhanced Performance of 3D Printed Highly Elastic Strain Sensors of Carbon Nanotube/Thermoplastic Polyurethane Nanocomposites via Non-Covalent Interactions. Compos. Part B Eng. 2019, 176, 107250. [CrossRef]

11. Zhao, C.; Xia, Z.; Wang, X.; Nie, J.; Huang, P.; Zhao, S. 3D-Printed Highly Stable Flexible Strain Sensor Based on Silver-CoatedGlass Fiber-Filled Conductive Silicon Rubber. Mater. Des. 2020, 193, 108788. [CrossRef]

12. Hales, S.; Tokita, E.; Neupane, R.; Ghosh, U.; Elder, B.; Wirthlin, D.; Kong, Y.L. 3D Printed Nanomaterial-Based Electronic, Biomedical, and Bioelectronic Devices. Nanotechnology 2020, 31, 172001. [CrossRef] [PubMed]

13. Alam, F.; Shukla, V.R.; Varadarajan, K.M.; Kumar, S. Microarchitected 3D Printed Polylactic Acid (PLA) Nanocomposite Scaffolds for Biomedical Applications. J. Mech. Behav. Biomed. Mater. 2020, 103, 103576. [CrossRef] [PubMed]

14. Penumakala, P.K.; Santo, J.; Thomas, A. A Critical Review on the Fused Deposition Modeling of Thermoplastic Polymer Composites. Compos. Part B Eng. 2020, 201, 108336. [CrossRef]

15. Yu, C.-T.; Lai, C.-C.; Wang, F.-M.; Liu, L.-C.; Liang, W.-C.; Wu, C.-L.; Chiu, J.-C.; Liu, H.-C.; Hsiao, H.-T.; Chen, C.-M. Fabrication of Thermoplastic Polyurethane (TPU)/Thermoplastic Amide Elastomer (TPAE) Composite Foams with Supercritical Carbon Dioxide and Their Mechanical Properties. J. Manuf. Process. 2019, 48, 127-136. [CrossRef]

16. Rostami, A.; Moosavi, M.I. High-Performance Thermoplastic Polyurethane Nanocomposites Induced by Hybrid Application of Functionalized Graphene and Carbon Nanotubes. J. Appl. Polym. Sci. 2020, 137, 48520. [CrossRef]

17. Zhu, Z.; Park, H.S.; McAlpine, M.C. 3D Printed Deformable Sensors. Sci. Adv. 2020, 6, eaba5575. [CrossRef]

18. Zhou, Y.; Zhan, P.; Ren, M.; Zheng, G.; Dai, K.; Mi, L.; Liu, C.; Shen, C. Significant Stretchability Enhancement of a Crack-Based Strain Sensor Combined with High Sensitivity and Superior Durability for Motion Monitoring. ACS Appl. Mater. Interfaces 2019, 11, 7405-7414. [CrossRef]

19. Xiang, D.; Zhang, X.; Han, Z.; Zhang, Z.; Zhou, Z.; Harkin-Jones, E.; Zhang, J.; Luo, X.; Wang, P.; Zhao, C.; et al. 3D Printed High-Performance Flexible Strain Sensors Based on Carbon Nanotube and Graphene Nanoplatelet Filled Polymer Composites. J. Mater. Sci. 2020, 55, 15769-15786. [CrossRef]

20. Wang, Z.; Zhang, Q.; Yue, Y.; Xu, J.; Xu, W.; Sun, X.; Chen, Y.; Jiang, J.; Liu, Y. 3D Printed Graphene/Polydimethylsiloxane Composite for Stretchable Strain Sensor with Tunable Sensitivity. Nanotechnology 2019, 30, 345501. [CrossRef] 
21. Xiang, D.; Zhang, X.; Harkin-Jones, E.; Zhu, W.; Zhou, Z.; Shen, Y.; Li, Y.; Zhao, C.; Wang, P. Synergistic Effects of Hybrid Conductive Nanofillers on the Performance of 3D Printed Highly Elastic Strain Sensors. Compos. Part A Appl. Sci. Manuf. 2020, 129, 105730. [CrossRef]

22. Kim, N.P. 3D-Printed Conductive Carbon-Infused Thermoplastic Polyurethane. Polymers 2020, 12, 1224. [CrossRef] [PubMed]

23. Kim, K.; Park, J.; Suh, J.; Kim, M.; Jeong, Y.; Park, I. 3D Printing of Multiaxial Force Sensors Using Carbon Nanotube (CNT)/Thermoplastic Polyurethane (TPU) Filaments. Sens. Actuators A Phys. 2017, 263, 493-500. [CrossRef]

24. Tan, L.J.; Zhu, W.; Zhou, K. Recent Progress on Polymer Materials for Additive Manufacturing. Adv. Funct. Mater. 2020, 30, 2003062. [CrossRef]

25. Kanoun, O.; Bouhamed, A.; Ramalingame, R.; Bautista-Quijano, J.R.; Rajendran, D.; Al-Hamry, A. Review on Conductive Polymer/CNTs Nanocomposites Based Flexible and Stretchable Strain and Pressure Sensors. Sensors 2021, 21, 341. [CrossRef]

26. Christ, J.F.; Aliheidari, N.; Ameli, A.; Pötschke, P. 3D Printed Highly Elastic Strain Sensors of Multiwalled Carbon Nanotube/Thermoplastic Polyurethane Nanocomposites. Mater. Des. 2017, 131, 394-401. [CrossRef]

27. Mousavi, S.; Howard, D.; Zhang, F.; Leng, J.; Wang, C.H. Direct 3D Printing of Highly Anisotropic, Flexible, Constriction-Resistive Sensors for Multidirectional Proprioception in Soft Robots. ACS Appl. Mater. Interfaces 2020, 12, 15631-15643. [CrossRef]

28. Vu, C.C.; Kim, J. Highly Sensitive E-Textile Strain Sensors Enhanced by Geometrical Treatment for Human Monitoring. Sensors 2020, 20, 2383. [CrossRef]

29. Wang, K.; Li, S.; Rao, Y.; Wu, Y.; Peng, Y.; Yao, S.; Zhang, H.; Ahzi, S. Flexure Behaviors of ABS-Based Composites Containing Carbon and Kevlar Fibers by Material Extrusion 3D Printing. Polymers 2019, 11, 1878. [CrossRef]

30. Wang, J.; Yang, B.; Lin, X.; Gao, L.; Liu, T.; Lu, Y.; Wang, R. Research of TPU Materials for 3D Printing Aiming at Non-Pneumatic Tires by FDM Method. Polymers 2020, 12, 2492. [CrossRef]

31. de León, A.S.; Domínguez-Calvo, A.; Molina, S.I. Materials with Enhanced Adhesive Properties Based on Acrylonitrile-ButadieneStyrene (ABS)/Thermoplastic Polyurethane (TPU) Blends for Fused Filament Fabrication (FFF). Mater. Des. 2019, $182,108044$. [CrossRef]

32. Yin, J.; Lu, C.; Fu, J.; Huang, Y.; Zheng, Y. Interfacial Bonding during Multi-Material Fused Deposition Modeling (FDM) Process Due to Inter-Molecular Diffusion. Mater. Des. 2018, 150, 104-112. [CrossRef]

33. Christ, J.F.; Aliheidari, N.; Pötschke, P.; Ameli, A. Bidirectional and Stretchable Piezoresistive Sensors Enabled by Multimaterial 3D Printing of Carbon Nanotube/Thermoplastic Polyurethane Nanocomposites. Polymers 2019, 11, 11. [CrossRef] [PubMed]

34. Rahman, M.T.; Moser, R.; Zbib, H.M.; Ramana, C.V.; Panat, R. 3D printed high performance strain sensors for high temperature applications. J. Appl. Phys. 2018, 123, 024501. [CrossRef]

35. Yao, X.; Luan, C.; Zhang, D.; Lan, L.; Fu, J. Evaluation of carbon fiber-embedded 3D printed structures for strengthening and structural-health monitoring. Mater. Des. 2017, 114, 424-432. [CrossRef] 